DOI: 10.11606/issn.2318-8855.v7i7p323-335

\title{
A mobilização do conceito de história na retórica de Leon Battista Alberti em Da Pintura (1435) e Sobre a família (1433) ${ }^{1}$
}

Bárbara Diniz Gonçalves*

Resumo: O presente trabalho tem como objetivo entender a abordagem da história segundo Leon Battista Alberti (1404-1472), tendo como ponto de partida dois documentos de sua autoria: o discurso em comentários Da Pintura, primeiro a sistematizar uma doutrina sobre o tema ao entrelaçar geometria e retórica, e o diálogo Sobre a família, que apresenta a ideia de uma família virtuosa como sendo a fundação da sociedade. Para isso, metodologicamente, partiu-se do princípio de que toda obra se constitui numa representação, como teoriza Roger Chartier. Em ambas as fontes, lemos o discurso de Alberti como uma construção social que nasce das práticas da realidade que o circunscreve e com ela interage. A partir da análise, pudemos identificar que as principais linhas de força constitutivas de ambos os documentos, apesar de suas diferenças no que concerne à temática e ao gênero textual, passam por uma retórica que mobiliza o conceito de história de forma muito semelhante, destacando sua função pedagógica e virtuosa. Concluímos que, utilizando-se de tal retórica, o autor contribuiu para a divulgação de uma nova narrativa histórica que recupera Cícero e se volta à moralidade humanista.

Palavras-chave: Alberti; História; Humanismo; Moralidade.

\footnotetext{
${ }^{1}$ Este artigo é fruto das discussões realizadas na disciplina de História Moderna I (Departamento de História do IFCH - Unicamp) ministrada pelo Prof. Dr. Rui Luis Rodrigues, a quem agradeço as orientações e a correção atenta. À Profa. Dra. Patricia Dalcanale Meneses e ao Prof. Dr. Gabriel Ferreira Zacarias, sou grata pela disposição para responder minhas dúvidas nessa e em outras situações.

* Graduanda em História pela Universidade Estadual de Campinas (Unicamp), com ênfase em História da Arte e Patrimônio Histórico e Cultural. Contato: bdg.barbara@gmail.com.
} 
Aquilo que escrevemos não escrevemos para nós, mas para toda humanidade. (ALBERTI, 1890, p. 293)

“O mundo visual e como representá-lo com linhas e cores, o mundo social e como analisá-lo em palavras"² (GRAFTON , 2002, p. 6, tradução própria): assim Anthony Grafton sintetizou os temas e formas que, inicialmente expressos na primeira peça de Alberti - uma comédia latina, Philodoxeos -, o ocupariam durante toda sua vida em todas suas diferentes formas de expressão: tratados, diálogos, sátiras, poemas ${ }^{3}$, pintura, arquitetura. Tais mundos visuais e sociais foram por ele representados de forma entrelaçada, por meio da junção de ideias e imagens e de linguagem letrada e artística, que antes existiram separadamente. Alguns dos fios que as enlaçam, os quais guiarão a análise a ser realizada no presente trabalho, são a beleza, compreendida como proporção, equilíbrio e decoro; a virtude, vida boa e beata ou bene beateque vivendum (CÍCERO, De republica, I, 39); e, finalmente, a história, narrativa moral que contextualiza uma obra em um sistema mais amplo de valores, que é aquele do pensamento humanista.

Esses três fios perpassam vários escritos do autor, embora sejam mais estudados no âmbito da estética e da arquitetura, por exemplo. Nesses estudos, Sobre a família é levado em conta, mas parece descolado da análise das outras obras - apesar de conter elementos comuns a elas e de ter tido seus quatro volumes escritos e publicados concomitantemente à primeira edição Da pintura. Partindo dessa percepção, o objetivo do presente trabalho é realizar uma breve análise quanto ao gênero dos textos, à relevância para o momento histórico da publicação e aos posicionamentos do autor no primeiro volume do diálogo Sobre a família e no tratado Da pintura. Depois, buscamos compará-los e entrelaçá-los, especialmente no que concerne à abordagem da história proposta por Alberti. Assim delimitados os objetivos, impõe-nos definir seu marco metodológico. Adotamos, ao examinar as práticas artísticas do Renascimento, o “critério do verossímil histórico - o que tais práticas

\footnotetext{
${ }^{2}$ No original: "The visual world and how to represent it with lines and colors, the social world and how to analyze it in words."

${ }^{3}$ São de autoria de Alberti os primeiros hexâmetros em italiano.
} 


\section{ensaios}

A mobilização do conceito de história na retórica de Leon Battista Alberti em Da pintura (1435) e Sobre a família (1433)

podem ter significado para os homens dos séculos XV e XVI, segundo costumes e preceitos de ampla circulação e difusão cultural" (CHARBEL, 2009, p. 6). Entendemos ainda que toda obra, independentemente de seu gênero - tratadístico, científico, artístico, literário - constitui-se em uma representação. Nesse sentido, o discurso de Alberti é lido como uma construção social que nasce das práticas da realidade que o circunscreve. Daí

o interesse manifestado pelo processo por intermédio do qual é historicamente produzido um sentido e diferenciadamente construída uma significação. Tal tarefa cruza-se, de maneira bastante evidente, com a da hermenêutica, quando se esforça por compreender como é que um texto pode "aplicar-se" à situação do leitor, por outras palavras, como é que uma configuração narrativa pode corresponder a uma refiguração da própria experiência (CHARTIER, 2002. p. 24).

Mas quem foi esse homem e, especificamente, qual é o filtro de seu tempo? Leon Battista Alberti (1404-1472) ${ }^{4}$ nasceu em Gênova, quando sua família estava exilada de Florença. Foi o segundo filho, ilegítimo, de Lorenzo di Benedetto Alberti e de Bianca Fieschi, nobre genovesa. Não se sabe muito acerca de seus primeiros estudos, mas é possível que eles tenham se realizado no Ginásio de Gasparino Barzizza, em Pádua, com forte influência da cultura da Antiguidade Clássica. Sabe-se que, em 1428, conseguiu seu diploma de direito canônico em Bolonha, apesar de tais estudos terem sido anteriormente interrompidos por um período de doenças e dificuldades em razão da morte de seu pai, em 1421. Nesse intervalo, em que foi vítima de contestações patrimoniais e de circunstâncias financeiras ruins, dedicou-se à física e à matemática, construindo assim o alicerce sobre o qual se apoiariam, mais tarde, suas obras técnicas, artísticas e arquitetônicas. Visto como protótipo do homem universal renascentista em Burckhardt ${ }^{5}$, Alberti de fato mobilizou uma erudição impressionante da tradição clássica greco-romana e, a partir dela, construiu pedagogias da

\footnotetext{
${ }^{4}$ Todas as informações biográficas foram consultadas em GRAYSON, 1999, pp. 35-70.

5 "Em Burckhardt, Alberti é o precursor de Leonardo da Vinci, o protótipo do homem universal, senhor de todas as suas possibilidades, representante da geração cuja ciência, cultura e razão haviam vencido o 'obscurantismo' medieval" (BRANDÃO, 2000, p. 29). Burckhardt trata elogiosamente de Alberti na Parte II de seu A Cultura do Renascimento na Itália, onde explana sobre o tema da personalidade no contexto do desenvolvimento do indivíduo. Para ele, "em todas as atividades em que se pode ganhar elogios, Leon Battista foi, desde a infância, o primeiro" (BURCKHARDT, 1991, p. 86-87).
} 
moral de seu tempo. Porém, somam-se a isso, como estudou Garin em contraste com a visão homogênea de Burckhardt, as críticas tecidas por Alberti acerca do próprio humanismo; de um humanismo cujo discurso ele percebe ser inútil, já que descolado da virtúb.

Partimos da percepção de que tanto o conceito de "Humanista" como o de "Renascimento" - e, consequentemente, de "homem do Renascimento" - comportam diversas interpretações possíveis, diferentes e até mesmo contraditórias. Portanto, aqui se considera que simplesmente definir Alberti como Humanista ou, ainda, anti-Humanista, nada nos auxilia para a compreensão de seu tempo ou dele próprio como ser histórico. Porém, afirmamos, com base na interpretação de Agnes Heller, que Alberti se encaixa no conceito dinâmico do homem que, segundo a autora, teria surgido no período compreendido como Renascimento. De acordo com ela, indivíduo e sociedade, permeados por identidades contraditórias e em mutação, passam a ter a sua própria história de desenvolvimento. "A relação entre o indivíduo e a situação torna-se fluída; o passado, o presente e o futuro transformam-se em criações humanas" (HELLER, 1982, p. 9). Para que o uso dos conceitos facilite esse entendimento, é importante expor que:

\begin{abstract}
"Humanista" e "homem do Renascimento" não são coincidentes. Stricto sensu, "humanismo" deriva dos studia humanitatis, as humanidades e ars liberalis que protagonizaram a educação do homem renascentista. Umanista e umanesimo, são termos que se difundiram, ao que parece, a partir da Universidade de Bolonha na segunda metade do século XV mas, já no final do século XIV, eram referidos ao estudo dos clássicos greco-romanos, ciceroniamente designado por studia humanitatis. (...). Um leitor dos clássicos não é necessariamente um "renascentista", a não ser que dê a estes estudos uma força intelectual, moral e política capaz de transformar o ser humano, a sociedade e a cidade do quattrocento; que faça da investigação do passado um modo de também investigar o presente, construir um novo futuro e um novo homem. (BRANDÃO, 2000, p. 150)
\end{abstract}

\footnotetext{
${ }^{6}$ Virtú: Virtude, faculdade, poder, capacidade de fazer algo; também pode se referir às artes liberais. Segundo Garin, "a educação humanística, como formação do homem completo através da revivida cultura clássica, vinha perdendo-se em uma educação puramente literária e aristocrática, contraposta à cultura concreta". (GARIN, 1952, p. 99). É a esses seus contemporâneos humanistas que Alberti se contrapõe.
} 
A mobilização do conceito de história na retórica de Leon Battista Alberti em Da pintura (1435) e Sobre a família (1433)

A dimensão humana da realidade, bem como a centralidade da experiência moral do homem é, pois, acentuada ${ }^{7}$ com o tipo de saber dos studia humanitatis. Este se centrava no estudo da gramática, da retórica, da história, da poética e da filosofia moral, ou seja, se diferenciava das disciplinas que compunham a escolástica: trivium (gramática, retórica e dialética) e quadrivium (aritmética, música, geometria e astronomia). Juntamente com os studia humanitatis como protagonistas da educação do homem renascentista - considerando as ressalvas aos termos - foram citadas as ars liberalis. Estas constituem também o filtro do tempo de Alberti, sendo parte relevante da conjuntura em que se inserem as obras que serão analisadas aqui. De acordo com Arthur Danto, tal liberação foi marcada pela modificação da consciência do que é arte, bem como dos papéis e funções do sujeito artista na sociedade. (DANTO, 1997, pp. 3-20). Essa mudança de narrativa sobre a história da arte aconteceu no momento específico do século XV e, assim, cumpre um papel educador e pedagógico da moral e do exercício das virtudes humanistas. Ainda segundo Danto, Alberti pertenceu à geração dos fundadores dessa narrativa e, como tal, contribuiu para a divulgação dessa nova consciência através de suas obras (DANTO, 2005, p.4).

Destas obras, as duas que serão analisadas a seguir, com já se disse, são Da pintura e Sobre a família ${ }^{8}$ Tal análise pretende conectá-las segundo os referidos três eixos - a beleza, a

\footnotetext{
${ }^{7}$ Há um debate na historiografia, que não cabe ser desenvolvido aqui, em torno das continuidades, rupturas e inovações do humanismo em relação ao Medievo, tanto como movimento de ideias quanto acerca de seu caráter político. O último caso foi identificado por Hans Baron na década de 1920 com o nome de humanismo cívico (BARON, 1966). Baron, nascido em Berlim em família judaica, era um ávido republicano em um contexto de emergência de formas políticas autoritárias. Sua leitura acerca do humanismo como um retorno a virtudes republicanas, portanto, está intrinsecamente relacionada com as necessidades de seu próprio momento histórico. Para mais informações sobre o tema, ver: NEDERMAN, Cary. "Civic Humanism". The Stanford Encyclopedia of Philosophy (Spring $2019 \quad$ Edition), Edward N. Zalta (ed.). Disponível em: https://plato.stanford.edu/archives/spr2019/entries/humanism-civic/ consultado em 27/04/2019.

${ }^{8}$ No presente trabalho, será citada a edição brasileira de Da Pintura publicada em 1999 pela Editora da Unicamp, que traz o texto integral; aos trechos seguem notas de seu referencial em toscano consultado em: ALBERTI, Leon Battista. De Pictura (versione latina e volgare). Laterza, 1980, a cura di Cecil Grayson. Disponível em: <http://www.dominiopublico.gov.br/download/texto/lb000014.pdf>. No caso do Sobre a família, no corpo do texto constam citações da versão brasileira de 1970 realizada pelo Editorial Grijalbo Ltda. Porém, dado que tal edição é parcial, aos trechos segue em nota seu referencial em italiano, consultado na versão integral da Editora Einaudi: ALBERTI, Leon Battista. I libri della Famiglia, Nuova Universale Einaudi, 1994. A cura di Ruggiero Romano, Alberto Tenenti, Francesco Furlan. Disponível em: < http://www.letteraturaitaliana.net/pdf/Volume_3/t49.pdf> consultado
} 
Bárbara Diniz Gonçalves

virtude e a história -, esta última cuja narrativa, ou discurso, permeia as outras duas e as encadeia em prol de um objetivo comum, a ser exposto após uma breve análise formal de ambas as obras.

Da pintura, redigido em 1435 ou $1436^{9}$, é o primeiro escrito sobre arte a expor uma doutrina sistematizada da pintura, que alia a própria pintura simultaneamente à geometria e à retórica. Há uma peculiaridade quanto a sua redação: ela é dupla, latina e toscana, e nem uma nem outra podem ser consideradas traduções, já que se percebem diferenças de conteúdo entre elas. Consideramos aqui a dupla redação "como se fossem paráfrases de si mesmas" (ZANCHETTA, 2014, p. 13), paráfrase sendo uma reescrita que concorre com o modelo, dizendo as mesmas coisas de forma diferente - nem melhor, nem pior - e por outros caminhos. Em suma, nenhuma das versões se reduz ao mesmo pensamento, ainda que convirjam para pensamentos semelhantes. Tal bilinguismo parece ainda constituir a defesa que Alberti faz da língua toscana, igualando-a ao latim quanto à utilidade e, ainda, quanto aos recursos nela presentes propensos à elaboração uma escrita douta ${ }^{10}$. No que concerne ao gênero da obra, podemos considerá-la um discurso em comentários (ZANCHETTA, 2014, p. 24). Discurso está no sentido do oratio dos filósofos sobre os quais escreve Cícero, a saber, ornado e eloquente cujos temas não são turbulentos. Tal discurso apresenta-se em forma de comentários que o esclarecem, fazendo com que Da Pintura seja "tanto uma exposição da

em 26/04/2019.

${ }^{9}$ A datação é feita com base na cronologia dos manuscritos, já que acredita-se que as versões posteriores são correções e refinamentos realizados por Alberti. Porém, a maior parte dos manuscritos não é datada. As duas datas seguras para o Da Pintura estão em anotações do próprio Alberti, uma feita em seu exemplar do Brutus de Cícero em que consta o dia 26 de Agosto de 1435 e outra que se encontra no fim no manuscrito toscano com dedicatória a Brunelleschi: "Fim. Louvor a deus. No dia 17 do mês de julho de 1436". (Alberti apud. ZANCHETTA, 2014, p. 3).

${ }^{10}$ Um exemplo de tal defesa, bem como do polimento da língua toscana em prol de escritas mais eruditas, é a Grammatichetta de Alberti, primeira gramática toscana, que apresenta uma doutrina para falar com correção. "Coisa semelhante fizeram os engenhos grandes e estudiosos, primeiro, com os gregos e depois com os latinos; e chamaram a estas admoestações para escrever aptamente e falar sem corruptela com o nome Gramática. Esta arte e o que ela é em nossa língua, ledes-me e entendê-la-eis." (Alberti, Grammatichetta, 1, apud. ZANCHETTA, 2014, p. 20) 
A mobilização do conceito de história na retórica de Leon Battista Alberti em Da pintura (1435) e Sobre a família (1433)

arte quanto uma coleção de coisas úteis à arte, como as noções matemáticas e óticas" (ZANCHETTA, 2014, p. 24).

Sobre a família, por sua vez, é um diálogo em quatro livros escritos durante da década de 1430. Nos dois primeiros, o autor tem como tema principal o matrimônio em geral e o cuidado com a educação dos filhos, bem como sobre que bases os pais devem se apoiar para fazê-la de forma virtuosa e prezando pelos bons costumes. O terceiro trata, sobretudo, do posicionamento do pai quanto à organização da família e à administração dos bens domésticos. O quarto, escrito posteriormente a uma revisão dos três primeiros, começa com uma explanação acerca de casamento, aprendizagem e amizade para, por fim, chegar aos três tipos de amizade propostos por Aristóteles: a boa, a agradável e a utilitária ${ }^{11}$. Aqui, o foco da análise será no primeiro volume: um diálogo entre um homem maduro e com família constituída, Adovardo, o qual aconselha o jovem Lionardo quanto à criação de filhos e à escolha de uma esposa - sendo a relação conjugal definida como a fundação da sociedade.

Sobre o diálogo como gênero textual, é relevante que tenha sido o escolhido por Alberti em detrimento de algum gênero mais prescritivo como o tratado, por exemplo. Ao empregálo - o diálogo -, o autor conscientemente desautoriza leituras únicas e, em alguns casos, enviesadas de seu texto, já que as respostas geralmente não apresentam um entendimento único e coeso do problema explorado. Ao contrário, continuamente são colocadas questões que não têm soluções definitivas (NAJEMY, 2008. pp. 135-152). De fato, o contraste entre otimismo e pessimismo, relevante em Sobre a família, talvez se deva, em parte, à experiência pessoal de Alberti como jovem órfão e exilado. Porém, é impressionante que, no conjunto da obra, o autor não só exalte a família Alberti como também construa, por meio de diálogos,

\footnotetext{
11 “Há, portanto, três espécies de amizade (...) Os amigos cuja afeição é baseada no interesse não amam um ao outro por si mesmos, e sim por causa de algum proveito que obtém um do outro. O mesmo raciocínio se aplica àqueles que se amam por causa do prazer; não é por seu caráter que gostamos das pessoas espirituosas, mas porque as achamos agradáveis. [...] A amizade perfeita é a existente entre as pessoas boas e semelhantes em termos de excelência moral; neste caso, cada uma das pessoas quer bem à outra de maneira idêntica, porque a outra pessoa é boa, e elas são boas em si mesmas." (ARISTÓTELES, Ética a Nicômaco, VIII, 3, 1156a-1156b)
} 


\section{Bárbara Diniz Gonçalves}

um ideal brilhante da família como núcleo social, cultural e, sobretudo, moral. Ou seja, a obra "representa um momento de otimismo e de plena confiança na capacidade do homem em criar em si e à sua volta uma vida harmoniosa, inspirada em elevados conceitos de virtude e operosidade" (GRAYSON, 1999, p. 40). Ou, segundo comentário de Franco Borsi,

Leon Battista sublinha a relação entre sua própria vocação e a ascendência familiar. (...) Na tentativa de reconhecer uma vocação comum a ele próprio e à família, Alberti tenta esconder sua porção deraciné, tenta superar a própria condição de alheio solitário, obrigado a viver do próprio trabalho e a repropor em termos dinásticos (...) sua própria origem: a condição, completamente moderna, de nobre decadente forçado a trabalhar. (BORSI, 1999, p. 9)

“A história é testemunha dos séculos, luz da verdade, vida da memória, mestra da vida, mensageira do passado. Que voz, se não a do orador, pode torná-la imortal?" (CíCERO apud. HARTOG, 2001, p.181) ${ }^{12}$ : eis a sentença inolvidável de Cícero em De Oratore, no qual é feita a afirmação da utilidade do relato histórico e a exaltação daquele que, a partir da oratória, permite à humanidade acessá-lo. Alberti a retoma e ressignifica nas duas obras, de forma a direcionar seus eixos de análise com o objetivo da liberação das artes e de sua consequente atribuição - no caso Da Pintura - "ao pintor da responsabilidade de atuar na construção de dramas que cumpram a função educadora na paidéia, no sistema moral, religioso e cultural da sociedade" (MORTIMER, 2015, p. 87). Em torno do conceito de história, Alberti escreveu em Da Pintura que:

A história, merecedora de elogio e admiração, deverá com seus atrativos se apresentar de tal forma ornada e agradável que conquistará, pelo deleite e movimento de alma, a todos que a contemplem, doutos e indoutos. A primeira coisa que proporciona prazer na história provém da variedade e copiosidade das coisas. [...] Para mim é muito copiosa a história em que em seus lugares se misturam velhos, jovens, meninos, mulheres, meninas, criancinhas, frangos, gatinhos, passarinhos, cavalos, ovelhas, construções, províncias e todas as coisas semelhantes. Louvarei toda e qualquer riqueza que pertença à história. (ALBERTI, 1999. p. 120) $)^{13}$

\footnotetext{
12 No original (editio stereotypa): “Historia uero testis temporum, lux ueritatis, uita memoriae, magistra uitae, nuntia uetustatis, qua uoce alia nisi oratoris immortalitati commendatur?" (CíCERO, De Oratore, 36)

13 "Sarà la storia, qual tu possa lodare e maravigliare, tale che con sue piacevolezze si porgerà sì ornata e grata, che ella terrà con diletto e movimento d'animo qualunque dotto o indotto la miri. Quello che prima dà voluttà nella
} 
A mobilização do conceito de história na retórica de Leon Battista Alberti em Da pintura (1435) e Sobre a família (1433)

Narrativa humana, drama que liga os componentes da pintura e se desenvolve na janela aberta no retângulo da superfície pictórica: eis a função da história nessa forma de arte. Função pedagógica, mas não doutrinária; função de "guia para o futuro" na apropriação de Cícero, segundo a qual, apesar de sua autonomia como reguladora do contexto dentro da representação artística, ela é ainda assim situada numa hierarquia e, nela, submetida à ética humanista do Renascimento. Descrição semelhante poderia ser feita acerca das responsabilidades do pai na criação dos filhos: função pedagógica, autonomia reguladora e simultaneamente estabelecida sob a virtude, a partir da qual se espera que a educação, como guia, gere frutos abundantes no futuro. Diz Lionardo, em resposta à dor de Adovardo derivada da preocupação com os meios de ensinar virtude aos filhos:

O homem tem como que inata a ideia da finalidade das coisas que o rodeiam. Ele tem em si uma força de percepção divina e maravilhosa que o faz distinguir as coisas boas das más, as saudáveis das nocivas, as que lhe servem e as que Ihe são prejudiciais. (...) E não há nos filhos sinais tão duvidosos, nem há pais tão ignorantes e primitivos que não cheguem a descobrir pelas atitudes naturais das crianças as tendências que poderão dar copiosos frutos, no futuro. (ALBERTI, 1970, p. 54) ${ }^{14}$

Tal "força de percepção divina e maravilhosa" (ALBERTI, 1970, p. 54) 15 $^{15}$ deveria, portanto, servir para que os homens se guiem em direção ao bene beateque vivendum (CÍCERO, De republica, I, 39): o melhor que um pai pode deixar a seu filho, assim como a finalidade última

istoria viene dalla copia e varietà delle cose. Come ne' cibi e nella musica sempre la novità e abondanza tanto piace quanto sia differente dalle cose antique e consuete, così l'animo si diletta d'ogni copia e varietà. Per questo in pittura la copia e varietà piace. Dirò io quella istoria essere copiosissima in quale a' suo luoghi sieno permisti vecchi, giovani, fanciulli, donne, fanciulle, fanciullini, polli, catellini, uccellini, cavalli, pecore, edifici, province, e tutte simili cose: e loderò io qualunque copia quale s'apartenga a quella istoria." (ALBERTI, De Pictura, II, 40)

${ }^{14}$ Como posto anteriormente, a edição brasileira de 1970 é parcial. Quando citada, seguirá em nota aos trechos o referencial da versão integral em italiano realizada pela Editora Einaudi. “E piú nell'ingegno e intelletto de' mortali have ancora inseminato la natura e inceso una cognizione e lume di infinite e occultissime ragioni di ferme e propinque cagioni, colle quali conosca onde e a che fine sieno nate le cose. E agiunsevi una divina e maravigliosa forza di sapere distinguere ed eleggere di tutte qual sia buona e qual nociva, qual mala, qual salutifera, quale accommodata e qual contraria. E vedi sí tosto come la pianta si scopre sopra della terra, cosí allora il pratico e diligente la conosce, e chi meno fusse pratico, colui alquanto piú tardi la conoscerebbe." (ALBERTI, 1994, pp. 46-47)

15 “(...) divina e maravigliosa forza di sapere” (ALBERTI, 1994, p. 46) 


\section{Bárbara Diniz Gonçalves}

da arte. Em Sobre a família, é dito: “Que os pais, portanto, incitem os filhos a seguir a virtude e atingir o bom nome, a concorrer para alcançar honra e louvores (...) e sintam-se felizes de possuir filhos desejosos de merecer louvor e aplauso" (ALBERTI, 1970, p. 62) ${ }^{16}$. Quanto ao âmbito artístico, para Alberti, como explana Carlos Brandão, deveria ser a função de um artista merecedor de "louvor e aplauso" combater a "alienação estética"17, ao fazer com que sua arte trabalhe em favor do desenvolvimento de "um mundo mais justo e mais feliz"18 (BRANDÃO, 2000, p. 136-140). Em prol de incitar tal objetivo ao artista, o argumento do aspecto intelectual envolvido na produção pictórica passa novamente pela história. É explícita, aqui, a visão da pintura, de seus elementos, personagens e técnicas, como instrumentos da mensagem histórica:

A maior obra do pintor não é um colosso, mas uma história. A história proporciona maior glória ao engenho do que o colosso. Os corpos são parte da história, os membros são partes dos corpos, a superfície é parte dos membros, portanto as primeiras partes da pintura são as superfícies. Da composição das superfícies nasce aquela graça nos corpos a que chamamos beleza. (ALBERTI, 1999, p.114) ${ }^{19}$

Emulando autoridades latinas como Quintiliano e Vitrúvio ${ }^{20}$, além do já referido Cícero, Alberti compreende tal beleza como uma conexão entre equilíbrio, decoro e proporção. Em

\footnotetext{
16 "Adunque e' padri con piacere incitino e' figliuoli a seguire virtú e fama, confortingli a concorrere ad attignere onore, festeggino chi vince, godano d'avere e' figliuoli presti e avidi a meritare lode e pregio." (ALBERTI, 1994, pp. 53-54)

${ }^{17}$ Alberti entende por "alienação estética" uma arte inútil à modificação da realidade. Nesse sentido, ele faz uma defesa do artista como agente promotor do sentimento cívico e divulgador da pedagogia ética humanista, em diálogo com outros campos culturais antes considerados superiores, como as litterae. Isso aconteceu no período histórico de mudança do status do artista, que passa a ter valorizado o aspecto intelectual de seu trabalho.

${ }^{18}$ Tal justiça e felicidade relacionam-se à mesma vida boa e beata, bene beateque vivendum (CíCERO, De republica, I, 39) defendida no Sobre a família como virtude maior a ser passada de pai para filho. Aqui, é o artista que deve tomar para si a responsabilidade de difundir tal virtude entre todos os membros da sociedade.

19 “Grandissima opera del pittore non uno collosso, ma istoria. Maggiore loda d'ingegno rende l'istoria che qual sia collosso. Parte della istoria sono i corpi, parte de' corpi i membri, parte de' membri la superficie. Le prime adunque parti del dipignere sono le superficie. Nasce della composizione delle superficie quella grazia ne' corpi quale dicono bellezza" (ALBERTI, De Pictura, II, 35)

${ }^{20}$ Quintiliano, nascido em 35 d.C., escreveu em Roma uma importante obra acerca da retórica intitulada De institutione oratoria, que pode ser traduzida como Educação do Orador. Como o próprio título sugere, sua ambição era de conjugar em uma única obra tudo aquilo que seria necessário à formação completa do orador, desde sua
} 


\section{A mobilização do conceito de história na retórica de Leon Battista Alberti em Da pintura (1435) e Sobre a família (1433)}

Alberti, portanto, a imitatio não é uma simples cópia da realidade e da natureza, realizada de forma descritiva. Ao contrário, trata-se de "procedimento prudencial de conhecimento das coisas do mundo, envolvendo inventio, dispositio e elocutio ${ }^{21}(\mathrm{CHARBEL}, 2009$, p. 10) - seleção do que dizer e de que forma dizer, a partir de vasto repertório, disposição harmônica dos elementos que compõem o drama e o dizer ornado. Em suma, "da mímesis do mundo fenomênico passa-se à do mundo moral. Simetricamente, a jusante da cena representada, os corpos pintados fazem a história dirigir-se à alma e não aos olhos do espectador" (BRANDÃO, 2000, p. 157). E é dirigindo-se à alma dos jovens que, utilizando-se dessa mesma concepção de mundo moral o personagem Lionardo, representando talvez o próprio Alberti, os aconselha:

Sejam assíduos aos estudos das letras, ó jovens; procurem suas alegrias no conhecimento das coisas passadas e dignas de memória; gravem em si estas memórias tão úteis à vida; alimentem seu intelecto de belas sentenças; deleitem-se com ornar sua alma de esplêndidos costumes; sejam civis no convívio com os outros e cheios de maravilhosas gentilezas; procurem, enfim, conhecer as coisas divinas e humanas. (ALBERTI, 1970, p. 85) 22

Finalmente, em passagens, Alberti parece considerar Da Pintura um monumento como estes que ele descreve e recomenda aos jovens - aquilo que traz algo à memória e é, ao mesmo tempo, uma obra grandiosa que preserva essa mesma memória.

infância até o fim de sua carreira. O tema da beleza e do decoro tem lugar no argumento sobre a eloquência (QUINTILIANO, De institutione oratoria, II, 16, 10) e sobre o modo de falar (QUINTILIANO, De institutione oratoria, II, 10, 13). Vitrúvio, arquiteto romano do século I a.C., escreveu o tratado arquitetônico De Architectura Libri Decem, no qual a ideia de decoro (decor) é conectada com a de proporção (symmetriae), onde reside a beleza (VITRÚVIO, De Architectura, VI, 2, 5).

${ }^{21}$ Os conceitos fazem parte do domínio da retórica e foram definidos por Cícero em Rhetorica ad Herennium e por Quintiliano em De institutione oratoria. Correspondem a aspectos que se complementam com o objetivo de formulação do discurso. Inventio é a fase de estabelecimento do conteúdo argumentativo; dispositio se refere à organização e à estruturação dos elementos do inventio; elocutio compreende o estilo e as qualidades da forma expressiva.

22 "Siate assidui; piacciavi conoscere le cose passate e degne di memoria; giovivi comprendere e' buoni e utilissimi ricordi; gustate el nutrirvi l'ingegno di leggiadre sentenze; dilettivi d'ornarvi l'animo di splendidissimi costumi; cercate nell'uso civile abondare di maravigliose gentilezze; studiate conoscere le cose umane e divine, quali con intera ragione sono accomandate alle lettere." (ALBERTI, 1994, p. 72) 


\section{ensaios}

\section{Bárbara Diniz Gonçalves}

A partir desse entrelaçamento de obras que, inicialmente, podem parecer distantes no tema e na forma, foi possível concluir que não apenas nos escritos sobre arte o autor contribuiu para a divulgação de uma nova narrativa histórica que recupera Cícero e se volta à moralidade humanista. Como um homem dinâmico que a partir da análise de suas obras podemos dizer que ele foi, filho de um tempo tão dinâmico quanto - apesar das continuidades com seu passado, talvez mais proeminentes mesmo que as rupturas -, Alberti buscou juntar res e verba, verdade e discurso, nos mais variados temas sobre os quais se propôs a escrever, segundo acreditava, para toda a humanidade.

\section{Fontes}

ALBERTI, Leon Battista. Da pintura. Campinas: Editora da Unicamp, 1999.

. De Pictura (versione latina e volgare). Laterza, 1980, a cura di Cecil Grayson.

. I libri della Famiglia, Nuova Universale Einaudi, 1994.

. Sobre a família: Livro I. São Paulo: Editorial Grijalbo Ltda., 1970.

\section{Referências bibliográficas}

ALBERTI, Leon Battista. Opera inedita et pacua separatim impressa. (a cura di Hieronymo Mancini). Florença: Sansoni, 1890.

ARISTÓTELES. Ética a Nicômacos. Brasília: Editoda da Universidade de Brasília, c1985.

BARON, Hans. The Crisis of the Early Italian Renaissance: civic humanism and republican liberty in an Age of classicism and tyranny. Princeton University Press, 1966.

BORSI, Franco. Leon Battista Alberti - L'Opera Completa, 1999.

BRANDÃO, Carlos Antônio Leite. O filósofo e o pintor: humanismo e anti-humanismo em Leon Battista Alberti. O que nos faz pensar, v. 19, n. 27, p. 149-164, 2010.

. Quid tum?: o combate da arte em Leon Battista Alberti. Editora UFMG, 2000.

BURCKHARDT, Jacob. A Cultura do Renascimento na Itália: um ensaio. Brasília: Editora da Universidade de Brasília, 1991.

CHARBEL, Felipe. “Representações do Belo no Quattrocento florentino: Leon Battista Alberti e Marsilio Ficino". In: Cadernos de estética aplicada, v. III, n. 6 (jan-jun/2009), pp. 1-22.

CHARTIER, Roger. A história cultural: entre práticas e representações. Algés: Difusão Editorial, 2002. 


\section{ensaios}

A mobilização do conceito de história na retórica de Leon Battista Alberti em Da pintura (1435) e Sobre a família (1433)

CÍCERO. De oratore. Edição de Kazimierz Kumaniecki. Editio stereotypa Stuttgart: B.G. Teubner, 1995. Scripta quae manserunt omnia. (Scripta quae manserunt omnia, fasc.3).

DANTO, Arthur. After the End of Art: Contemporary Art and the Pale of History. Princeton: Princeton University Press, 1997.

. A transfiguração do lugar comum. São Paulo: Cosac Naify, 2005.

GARIN, Eugenio. Idade Média e Renascimento. Lisboa: Editorial Estampa, 1994 . L'umanesimo italiano. Bari: Gius. Laterza \& Figli, 1952.

GRAFTON, Anthony. Leon Battista Alberti: Master Builder of the Italian Renaissance. Harvard University Press, 2002.

GRAYSON, Cecil. Introdução. In: ALBERTI, Leon Battista. Da pintura. Campinas: Editora da Unicamp, 1999. pp. 35-70.

HARTOG, François. A história de Homero a Santo Agostinho. Belo Horizonte: Ed. UFMG, 2001. HELLER, Agnes. O homem do Renascimento. Lisboa: Editorial Presença, 1982.

NAJEMY, John. "Alberti on Love: Musings on Private Transgression and Public Discipline." In Power, Gender, and Ritual in Europe and the Americas: Essays in Memory of Richard C. Trexler. Toronto: Centre for Reformation and Renaissance Studies, 2008.

NEDERMAN, Cary, "Civic Humanism", The Stanford Encyclopedia of Philosophy (Spring 2019 Edition), Edward Z. Zalta (ed.), Disponível em: https://plato.stanford.edu/archives/spr2019/entries/humanism-civic/ consultado em 27/04/2019.

MORTIMER, Junia. Nas margens da modernidade: duas abordagens da história. Coimbra: Imprensa da Universidade de Coimbra, 2015.

NOUGARET, Louis. Traité de métrique latine classique. São Paulo: Martins Fontes, 1992.

OLIVEIRA, Roberto Silva de. A cidade e o pensamento político de Leon Battista Alberti no De Re Aedificatoria e outros escritos. 2010. 232f. Dissertação (Mestrado) - Faculdade de Arquitetura e Urbanismo, UFBA. Salvador, 2010.

PENNACINI, A. Ed. Marci Fabii Quintiliani Institutio Oratoria. Turim: Einaudi, 2001.

SKINNER, Quentin. As fundações do pensamento político moderno. São Paulo: Companhia das Letras, 1996.

VITRUVE. De L'Architecture. Livre VI. Paris: Les Belles Lettres, 2004.

ZANCHETTA, Ricardo. Da Pintura de Leon Battista Alberti: comentário e tradução do primeiro livro. 2014. 305f. Dissertação (Mestrado em Filosofia) - Faculdade de Filosofia, Letras e Ciências Humanas, Universidade de São Paulo, São Paulo, 2014. 